\title{
Synthesis, characterization and antimicrobial activity, and applications of new azo pyridone disperse dyes on polyester fabric
}

\author{
Alya Al-Etaibi a,*, Morsy Ahmed El-Apasery b, Huda Mahmoud c, and Nouria Al-Awadi d \\ a Natural Science Department, College of Health Science, Public Authority for Applied Education and Training, Fayha, 72853, Kuwait \\ b Dyeing, Printing and Textile Auxiliaries Department, Textile Research Division, National Research Centre, 12622, Dokki, Giza, Egypt \\ c Department of Biological Sciences, Faculty of Science, Kuwait University, Safat, 13060, Kuwait \\ d Department of Chemistry, Faculty of Science, Kuwait University, Safat, 13060, Kuwait
}

*Corresponding author at: Natural Science Department, College of Health Science, Public Authority for Applied Education and Training, Fayha, 72853, Kuwait. Tel.: +965.99807246. Fax: +965.24832657. E-mail address: alya_aletaibi@yahoo.com (A. Al-Etaibi).

\section{ARTICLE INFORMATION}

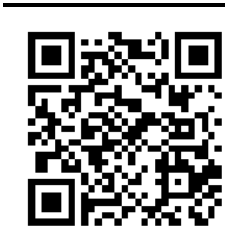

DOI: 10.5155 /eurjchem.5.2.321-327.969

Received: 12 November 2013

Received in revised form: 24 December 2013

Accepted: 29 December 2013

Online: 30 June 2014

\section{KEYWORDS}

\section{Pyridones}

Dyeing behavior

Polyester fabrics

Fastness properties

Antimicrobial activity

Microwave irradiation

\section{Introduction}

Disperse polyester is the most hydrophobic of all common fibres and is usually dyed with disperse dyes. The major disperse dyes are azo dyes, especially monoazo dyes [1], they have relatively simple manufacturing processes and can be generated by varying the diazo and coupling components, which provide a very wide colour range of high colour strength [2]. Pyridones as coupling components have been shown to be important colorants for various dyes in industrial applications. Furthermore, $N$-substituted pyridone azo disperse dyes show good colour strength, and excellent light fastness [3]. In addition, pyridones were found to be used widely in textile industry for the preparing azo disperse dyes [4]. The visible absorption wavelength of these dyes are generally in the yellow to orange range due to poorly delocalized electrons in the heterocyclic ring; however, some of these dyes show more deeper colour strength and shades such as red or violet or brown $[5,6]$. On the other hand, the use of heteroaromatic amines as diazo components in the generation of disperse dyes having essentially colour deepening effect is well established [7]. Pyridinone disperse dye derivatives have found many applications on different fabrics [8-10].
For further investigation in the synthesis of pyridinone disperse dyes [11], this paper reports the synthesis of 1,4diethyl-2,6-dioxo-1,2,5,6-tetrahydropyridine-3-carbonitrile, 9, using microwave irradiation as energy source. The latter 9 was served as a good precursor for the synthesis of novel arylhydrazono-1,4-diethyl-2,6-dioxo-1,2,5,6-tetrahydropyridine3 -carbonitriles disperse dyes for the dyeing of polyester fabrics. This study, also investigated the antimicrobial activity of the synthesized disperse dyes against Bacillus subtilis and Staphylococcus aureus (Gram positive bacteria), Escherichia coli and Pseudomonas aeruginosa (Gram negative bacteria), and Candida albicans (Yeast).

\section{Experimental}

\subsection{Instrumentation}

Melting points were recorded on a Gallenkamp apparatus. IR spectra were recorded using $\mathrm{KBr}$ pellets on a JASCO FTIR6300 FT-IR spectrophotometer. ${ }^{1} \mathrm{H}$ and ${ }^{13} \mathrm{C}$ NMR spectra were recorded on Bruker DPX $400 \mathrm{MHz}$ super-conducting NMR spectrometer with proton spectra measured at 400 , and carbon spectra at $100 \mathrm{MHz}$. 


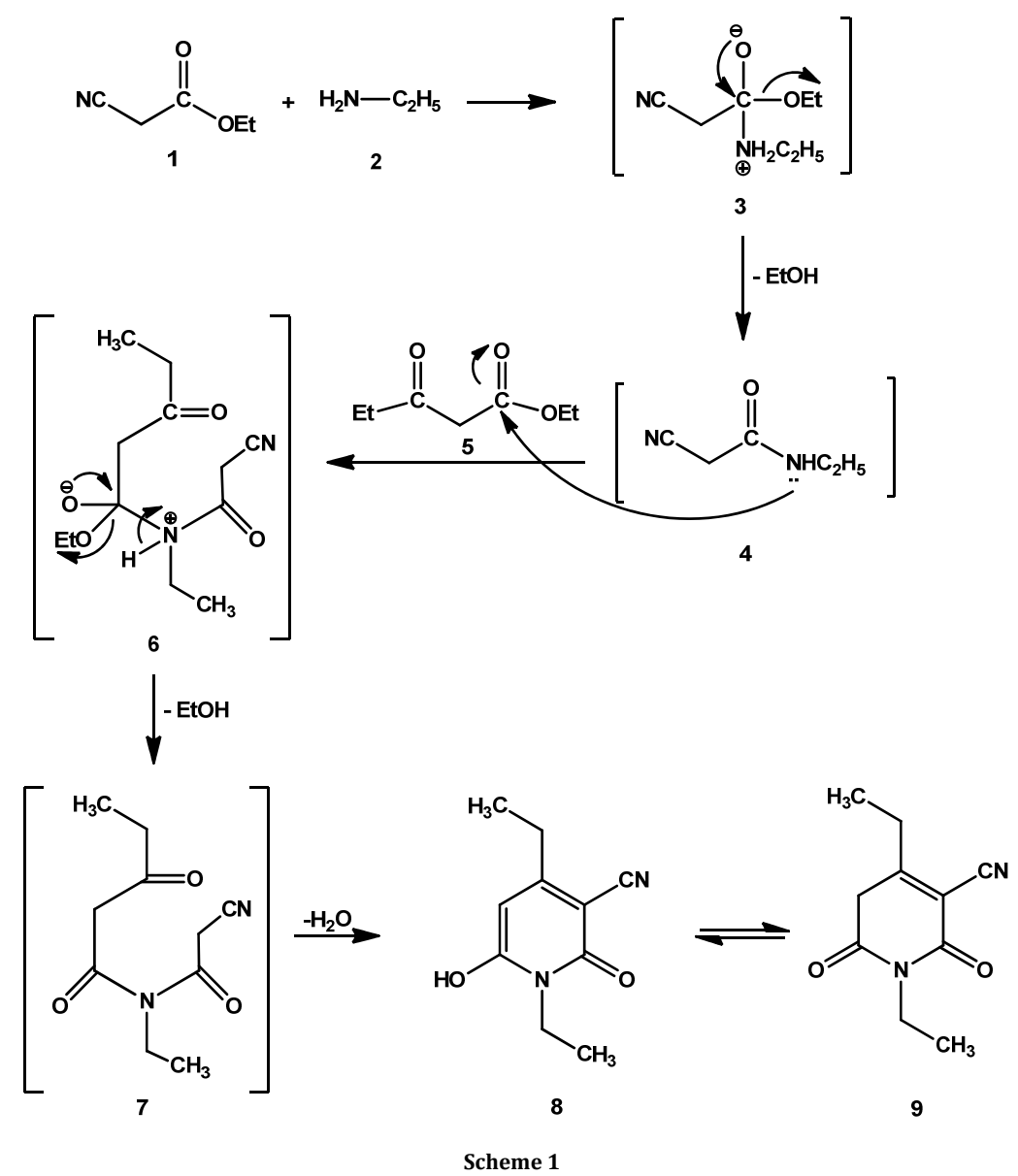

Mass spectra were measured on a high resolution GC/MS DFS-Thermo, of an electron ionization property (EI, $70 \mathrm{EV}$ ). Microanalyses were performed on Elemental-Vario Micro cube Analyzer. The microwave oven used is a single mode cavity Explorer Microwave (CEM Corporation, Matthews, NC, USA). The crystal structure of compounds $10 \mathrm{~g}$ was determined by Bruker AXS X8 Prospector Single Crystal X-Ray Diffractometer at Kuwait University.

\subsection{1,4-Diethyl-2,6-dioxo-1,2,5,6-tetrahydropyridine-3- carbonitrile (9)}

A mixture of ethyl cyanoacetate $(10 \mathrm{mmol})$, methyl propionylacetate $(10 \mathrm{mmol})$, ethyl amine $(15 \mathrm{mmol})$ and silica gel $(2.00 \mathrm{~g})$ was irradiated under microwave irradiation at 160 ${ }^{\circ} \mathrm{C}$ for $20 \mathrm{~min}$. The reaction progress was monitored by TLC. The mixture was extracted with methanol. The solvent was removed under vacuum. For further purification, hot water (15 $\mathrm{mL}$ ) was added, then acidified with hydrochloric acid. The precipitate was collected, washed with water and dried to give compound 9 (Scheme 1). Compound 9 has been confirmed by our recently reported spectroscopic data [11].

\subsection{General procedure for the synthesis of azo disperse dyes (10a-g)}

A cold solution of aryldiazonium salt $(10 \mathrm{mmol})$, prepared by adding a solution of sodium nitrite $\left(1.00 \mathrm{~g}\right.$ in $\left.10 \mathrm{~mL} \mathrm{H}_{2} \mathrm{O}\right)$ to a cold solution of arylamine hydrochloride $(10 \mathrm{mmol})$ with stirring as described earlier [11]. The aryldiazonium salts were added to the cold solution of compound $\mathbf{9}(10 \mathrm{mmol})$ in ethanol
$(20 \mathrm{~mL})$ containing sodium acetate $(2.00 \mathrm{~g})$. The mixture was stirred at room temperature for one hour. The solid product so formed was collected by filtration and recrystallized from ethanol to furnish compounds 10a-g (Scheme 2).

Compounds 10a, 10b, 10c and $10 \mathrm{f}$ have been confirmed by our recently reported spectroscopic data [11].

1,4-Diethyl-5-(2-(4-hydroxyphenyl)hydrazono)-2,6-dioxo-1,2, 5,6-tetrahydropyridine-3-carbonitrile (10d): Colour: Dark orange. Yield: $68 \%$. M.p.: $293{ }^{\circ} \mathrm{C}$. FT-IR (KBr, v, cm-1): 3317 $(\mathrm{OH}), 3196(\mathrm{NH}), 2220(\mathrm{CN}), 1658,1620$ (CO). ${ }^{1} \mathrm{H}$ NMR (400 MHz, DMSO- $\left.d_{6}, \delta, \mathrm{ppm}\right): 1.12\left(\mathrm{t}, 3 \mathrm{H}, J=7.2 \mathrm{~Hz}, \mathrm{CH}_{3}\right), 1.23(\mathrm{t}, 3 \mathrm{H}$, $\left.J=7.8 \mathrm{~Hz}, \mathrm{CH}_{3}\right), 2.89\left(\mathrm{q}, 2 \mathrm{H}, J=7.8 \mathrm{~Hz}, \mathrm{CH}_{2}\right), 3.86(\mathrm{q}, 2 \mathrm{H}, J=7.8$ $\left.\mathrm{Hz}, \mathrm{CH}_{2}\right), 6.87(\mathrm{~d}, 2 \mathrm{H}, J=7.2 \mathrm{~Hz}, \mathrm{Ar}-\mathrm{H}), 7.56(\mathrm{~d}, 2 \mathrm{H}, J=7.2 \mathrm{~Hz}$, Ar-H), 9.96 (s, 1H, OH, D 20 exchangeable), 14.00 (s, 1H, NH, $\mathrm{D}_{2} \mathrm{O}$ exchangeable). ${ }^{13} \mathrm{C}$ NMR (100 MHz, DMSO- $\left.d_{6}, \delta, \mathrm{ppm}\right): 12.6$ $\left(\mathrm{CH}_{3}\right), 14.1\left(\mathrm{CH}_{3}\right), 23.5\left(\mathrm{CH}_{2}\right), 34.3\left(\mathrm{CH}_{2}\right), 115.1,116.4,119.3$, $120.3,157.4,160.1,160.6,163.6 . \mathrm{MS}(\mathrm{m} / \mathrm{z},(\%)): 312\left(\mathrm{M}^{+}, 100\right)$. Anal. calcd. for $\mathrm{C}_{16} \mathrm{H}_{16} \mathrm{~N}_{4} \mathrm{O}_{3}$ : C, 61.53; H, 5.16; N, 17.94. Found: $\mathrm{C}$, 61.35; H, 5.20; N, 17.80\%.

5-(2-(4-Bromophenyl)hydrazono)-1,4-diethyl-2,6-dioxo-1,2,5, 6-tetrahydropyridine-3-carbonitrile (10e): Colour: Dark yellow. Yield: 61\%. M.p.: 211-213 ${ }^{\circ} \mathrm{C}$. FT-IR (KBr, v, cm-1): $3449(\mathrm{NH})$, 2221 (CN), 1682, 1628 (CO). ${ }^{1} \mathrm{H}$ NMR (400 MHz, DMSO-d $d_{6} \delta$, ppm): $1.12\left(\mathrm{t}, 3 \mathrm{H}, J=7.2 \mathrm{~Hz}, \mathrm{CH}_{3}\right), 1.24\left(\mathrm{t}, 3 \mathrm{H}, J=7.2 \mathrm{~Hz}, \mathrm{CH}_{3}\right)$, $2.90\left(\mathrm{q}, 2 \mathrm{H}, J=7.8 \mathrm{~Hz}, \mathrm{CH}_{2}\right), 3.86\left(\mathrm{q}, 2 \mathrm{H}, J=7.8 \mathrm{~Hz}, \mathrm{CH}_{2}\right), 7.67(\mathrm{~s}$, $4 \mathrm{H}, \mathrm{Ar}-\mathrm{H}), 14.53$ (s, 1H, NH, $\mathrm{D}_{2} \mathrm{O}$ exchangeable). ${ }^{13} \mathrm{C}$ NMR (100 MHz, DMSO- $\left.d_{6}, \delta, \mathrm{ppm}\right): 12.6\left(\mathrm{CH}_{3}\right), 14.0\left(\mathrm{CH}_{3}\right), 23.6\left(\mathrm{CH}_{2}\right), 34.4$ $\left(\mathrm{CH}_{2}\right), 114.7,119.1,119.3,122.2,132.5,160.0,163.8 . \mathrm{MS}(\mathrm{m} / \mathrm{z}$, (\%)): $375\left(\mathrm{M}^{+}, 80\right)$. Anal. calcd. for $\mathrm{C}_{16} \mathrm{H}_{15} \mathrm{BrN}_{4} \mathrm{O}_{2}$ : C, 51.22; $\mathrm{H}$, 4.03; N, 14.93. Found: 51.08; H, 4.06; N, 14.85\%. 
<smiles>[X]c1ccc(NN=C2C(=O)N(CC)C(=O)C(C#N)=C2CC)cc1</smiles>

9

10<smiles>CCC1=C(C)C(=O)N(CC)C(=O)/C1=N\Nc1ccc(N/N=C2/C(=O)N(CC)C(=O)C(C#N)=C2CC)cc1</smiles>

$10 \mathrm{a}$

10b

$10 \mathrm{c}$<smiles>CCC1=C(C)C(=O)N(CC)C(=O)C1=NNc1ccc(NN=C2C(=O)N(CC)C(=O)C(C#N)=C2CC)cc1</smiles><smiles>CCC1=C(C#N)C(=O)N(CC)C(=O)/C1=N\Nc1ccc([N+](=O)[O-])cc1</smiles>

Scheme 2

1,4-Diethyl-5-(2-(4-nitrophenyl)hydrazono)-2,6-dioxo-1,2,5, 6-tetrahydropyridine-3-carbonitrile (10g): Colour: Dark yellow. Yield: $84 \%$. M.p.: $259^{\circ} \mathrm{C}$. FT-IR (KBr, v, cm-1): $3449(\mathrm{NH}), 2224$ (CN), 1677, 1633 (CO). ${ }^{1} \mathrm{H}$ NMR (400 MHz, DMSO- $\left.d_{6}, \delta, \mathrm{ppm}\right)$ : $1.13\left(\mathrm{t}, 3 \mathrm{H}, J=7.2 \mathrm{~Hz}, \mathrm{CH}_{3}\right), 1.25\left(\mathrm{t}, 3 \mathrm{H}, J=7.8 \mathrm{~Hz}, \mathrm{CH}_{3}\right), 2.92(\mathrm{q}$, $\left.2 \mathrm{H}, J=7.8 \mathrm{~Hz}, \mathrm{CH}_{2}\right), 3.85\left(\mathrm{q}, 2 \mathrm{H}, J=7.2 \mathrm{~Hz}, \mathrm{CH}_{2}\right), 7.88(\mathrm{~d}, 2 \mathrm{H}, J=$ $9.0 \mathrm{~Hz}, \mathrm{Ar}-\mathrm{H}), 8.30$ (d, 2H, $J=9.0 \mathrm{~Hz}, \mathrm{Ar}-\mathrm{H}), 14.42(\mathrm{~s}, 1 \mathrm{H}, \mathrm{NH}$, $\mathrm{D}_{2} \mathrm{O}$ exchangeable). ${ }^{13} \mathrm{C}$ NMR (100 MHz, DMSO- $\left.d_{6}, \delta, \mathrm{ppm}\right): 12.5$ $\left(\mathrm{CH}_{3}\right), 13.9\left(\mathrm{CH}_{3}\right), 23.6\left(\mathrm{CH}_{2}\right), 34.6\left(\mathrm{CH}_{2}\right), 114.7,116.1,117.5$, $124.2,125.5,125.6,144.4,159.8,161.0,163.7 . \mathrm{MS}(\mathrm{m} / \mathrm{z},(\%))$ : $341\left(\mathrm{M}^{+}, 100\right)$. Anal. calcd. for $\mathrm{C}_{16} \mathrm{H}_{15} \mathrm{~N}_{5} \mathrm{O}_{4}: 56.30 ; \mathrm{H}, 4.43 ; \mathrm{N}$, 20.52. Found: 55.94; H, 4.47; N, 20.05\%.

\subsection{High temperature dyeing method (HT)}

\subsubsection{Materials}

Polyester $100 \%$ was used. The fabric was treated before dyeing with a solution containing non-ionic detergent $5 \mathrm{~g} / \mathrm{L}$ (Hostapal CV, Clariant, Egypt) and sodium carbonate $(2 \mathrm{~g} / \mathrm{L})$ in a ratio of $50: 1$ at $60{ }^{\circ} \mathrm{C}$ for $30 \mathrm{~min}$, thoroughly washed with water, and air dried at room temperature.

\subsubsection{Dyeing}

A dispersion of the dye was produced by dissolving the appropriate amount of dye ( $2 \%$ shade) in $2 \mathrm{~mL}$ DMF and then added drop wise with stirring to the dye bath (Liquor ration 50:1) containing sodium lignin sulfonate as dispersing agent. The ratio of dispersing agent to dyestuff is 4 to 1 . The $\mathrm{pH}$ of the dye bath was adjusted to 4.5 using aqueous acetic acid and the wetted-out polyester fabrics were added. Dyeing was performed by raising the dye bath temperature to $130^{\circ} \mathrm{C}$ under pressure in a dyeing machine at a rate of $15^{\circ} \mathrm{C} / \mathrm{min}$, holding at this temperature for $60 \mathrm{~min}$ and then cooling to $50{ }^{\circ} \mathrm{C}$. After dyeing, the fabrics were thoroughly washed and subjected to surface reduction clearing $((2 \mathrm{~g} \mathrm{NaOH}+2$ g sodium hydrosulphite)/L and soaped with $2 \%$ nonionic detergent and ammonia $(\mathrm{pH}=8.5)$ to improve washing fastness). The samples were heated in this solution for $30 \mathrm{~min}$ at $50{ }^{\circ} \mathrm{C}$ and then thoroughly washed and air-dried.

\subsection{Colour measurements and analyses}

\subsubsection{Colour measurements}

The colorimetric parameters of the dyed polyester fabrics were determined on a reflectance spectrophotometer. The colour yields of the dyed samples were determined by using the light reflectance technique performed on UV-Vis spectrophotometer. The colour strengths, expressed as K/S values, were determined by applying the Kubelka-Mink equation $[11,12]$. 


\subsubsection{Fastness tests}

\subsubsection{Fastness to washing}

After washing using $5 \mathrm{~g} / \mathrm{L}$ of the non-ionic detergent (Hostapal CV, Clariant, Egypt) and $2 \mathrm{~g} / \mathrm{L}$ of sodium carbonate, the dyed fabrics were tested by using ISO standard methods [13]. A specimen of dyed polyester fabric was stitched between two pieces of undyed cotton and wool fabrics, all of equal length, and then washed at $50{ }^{\circ} \mathrm{C}$ for $30 \mathrm{~min}$. The changes in color were assessed according to the gray scale [14].

\subsubsection{Fastness to perspiration}

The samples were prepared by stitching a piece of dyed polyester fabric between two pieces of cotton and wool fabrics, all of equal length, and then immersed in the acid or alkaline solution for $30 \mathrm{~min}$. The acid solution $(\mathrm{pH}=4.5)$ contains sodium chloride $(10 \mathrm{~g} / \mathrm{L})$, sodium dihydrogen orthophosphate $(1 \mathrm{~g} / \mathrm{L})$ and histidine monohydrochloride $(0.25 \mathrm{~g} / \mathrm{L})$. The alkaline solution $(\mathrm{pH}=8.7)$ contains sodium chloride $(10 \mathrm{~g} / \mathrm{L})$, disodium orthophosphate $(1 \mathrm{~g} / \mathrm{L})$ and histidine monohydro chloride $(0.25 \mathrm{~g} / \mathrm{L})$. The changes in color were assessed according to the gray scale [14].

\subsubsection{Fastness to light}

Light fastness was determined by exposing the dyed polyester on a Xenotest 150 (Original Hanau, chamber temperature $25-30{ }^{\circ} \mathrm{C}$, black panel temperature $60^{\circ} \mathrm{C}$, relative humidity 50-60\%, and dark glass (UV) filter system) for $40 \mathrm{~h}$. The changes in color were assessed according to the blue scale [14].

\subsection{Antimicrobial activities test}

The antimicrobial activities of arylhydrazonals and disperse dyes were tested using Agar-well diffusion technique $[14,15]$, against five different microbial cultures. Pure cultures of Bacillus subtilis and Staphylococcus aureus (Gram positive bacteria), Escherichia coli and Pseudomonas aeruginosa (Gram negative bacteria), and Candida albicans (Yeast) were involved in the test. An aliquot of $0.1 \mathrm{~mL}$ of each bacterial strain was inoculated and spread on nutrient agar (NA) while $0.1 \mathrm{~mL}$ of the yeast was spread on potato dextrose agar (PDA). The inoculated plates were supplied with $100 \mu \mathrm{L}$ of each of the tested arylhydrazonals and disperse dyes with a total final concentration of $100 \mathrm{mg} / \mathrm{mL}$. The arylhydrazonals and disperse dyes were included in $4 \mathrm{~mm}$ wells produced by sterile cork borer. The NA plates were incubated at $37^{\circ} \mathrm{C}$ for 24 hours while PDA plates were incubated at $25{ }^{\circ} \mathrm{C}$ for $24-48 \mathrm{~h}$. The zones of inhibition around the wells were determined and the average based on 3 replica was recorded. Cycloheximide and ampicillin both used as references in the experiment where cycloheximide known to inhibit eukaryotic organisms while Ampicillin inhibit prokaryotes. Picture were taken for some of the plates after 24,72 and $120 \mathrm{~h}$ using digital camera to determine the antimicrobial activity nature of the disperse dyes if they were cytolytic or cytostatic.

\section{Results and discussion}

\subsection{Synthesis and structural characterization}

Recently, we have reported the synthesis of some disperse dyes based on pyridone moiety [11]. Herein, in an attempt to study the biological activity profiles, and evaluate their dyeing behaviour, we report a new strategy for the preparation of 1,4diethyl-2,6-dioxo-1,2,5,6-tetrahydropyridine-3-carbonitrile (9) under microwave irradiation as an energy source. We introduce a one-pot three component condensation for the synthesis of compound 9 under solvent-free condition, we carried out the reaction of ethyl cyanoacetate, with ethyl amine, and methyl propionylacetate on the surface of silica gel as acatalyst at $160^{\circ} \mathrm{C}$ for $20 \mathrm{~min}$, under microwave irradiation. Compound 9 was produced in $(74 \%)$ yield. This compound may be exist in another tautmeric form $\mathbf{8}$ and in solution there is a very fast equilibration between them [16]. It seems that in situ reaction of ethyl cyanoacetate and ethyl amine leads to the amide derivative $\mathbf{4}$ that then reacted with methyl propionylacetate afforded compound $\mathbf{9}$. The one-pot nature of this procedure makes it an acceptable alternative to multistep approaches that offers considerable advantages, such as elimination of solvents, high yields, short reaction times (Scheme 1).

Coupling of compound $\mathbf{9}$ with aromatic diazonium salts afforded the corresponding disperse dyes 10a-g. Structural assignment of dye $\mathbf{1 0 g}$ was confirmed unambiguously by the $\mathrm{X}$ ray crystallographic data provided below (Scheme 2), (Figure 1), (Table 1-3).

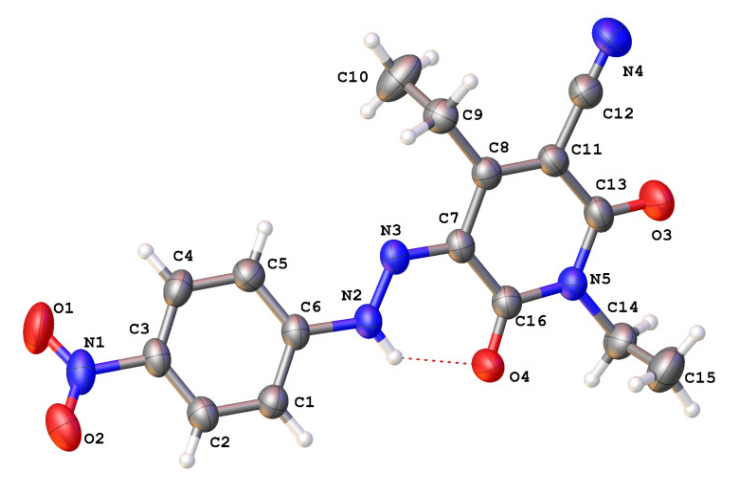

Figure 1. X-ray crystal structure of compound $10 \mathrm{~g}$.

Table 1. Crystal data and structure refinement for compound $\mathbf{1 0 g}$.

\begin{tabular}{|c|c|}
\hline & \\
\hline Empirical formula & $\mathrm{C}_{16} \mathrm{H}_{15} \mathrm{~N}_{5} \mathrm{O}_{4}$ \\
\hline Formula weight & 341.33 \\
\hline Temperature/K & $296(2)$ \\
\hline Crystal system & Monoclinic \\
\hline Space group & Pc \\
\hline $\mathrm{a} / \AA$ & $4.9132(4)$ \\
\hline $\mathrm{b} / \AA$ & $13.1940(10)$ \\
\hline $\mathrm{c} / \AA ̊$ & $12.3592(9)$ \\
\hline$\alpha /{ }^{\circ}$ & 90 \\
\hline$\beta /{ }^{\circ}$ & $99.328(6)$ \\
\hline$\gamma /{ }^{\circ}$ & 90 \\
\hline Volume $/ \AA^{3}$ & $790.59(11)$ \\
\hline $\mathrm{Z}$ & 2 \\
\hline$\rho_{\text {calcmg }} / \mathrm{mm}^{3}$ & 1.434 \\
\hline $\mathrm{m} / \mathrm{mm}^{-1}$ & 0.893 \\
\hline$F(000)$ & 356.0 \\
\hline Crystal size $/ \mathrm{mm}^{3}$ & $0.23 \times 0.05 \times 0.02$ \\
\hline $2 \Theta$ range for data collection & 6.7 to $133.24^{\circ}$ \\
\hline Index ranges & $-4 \leq h \leq 5$ \\
\hline & $-13 \leq k \leq 15$ \\
\hline & $-14 \leq l \leq 14$ \\
\hline Reflections collected & 3375 \\
\hline Independent reflections & $1972[\mathrm{R}(\mathrm{int})=0.0200]$ \\
\hline Data/restraints/parameters & $1972 / 4 / 228$ \\
\hline Goodness-of-fit on $\mathrm{F}^{2}$ & 1.049 \\
\hline Final $R$ indexes $[I>=2 \sigma(I)]$ & $\mathrm{R}_{1}=0.0361, \mathrm{wR} 2=0.0853$ \\
\hline Final $\mathrm{R}$ indexes [all data] & $\mathrm{R}_{1}=0.0445, \mathrm{wR} 2=0.0911$ \\
\hline Largest diff. peak/hole / e $\AA^{-3}$ & $0.13 /-0.16$ \\
\hline Flack parameter & $0 .(2)$ \\
\hline
\end{tabular}

Dyes 10a-g can exist in three possible tautomeric forms, namely the azo-keto forms, the azo-enol forms, and the hydrazo-keto forms as shown in (Scheme 3). The FT-IR spectra of most dyes shows a broad NH hydrazone band in the region 3449-3436 $\mathrm{cm}^{-1}$, FT-IR spectra of dyes 10a-g did not show any broad band for hydroxyl group which suggests that these dyes dominantly exist in the solid state in the hydrazone tautomeric form which was also confirmed by ${ }^{1} \mathrm{H}$ NMR. 
Table 2. Bond lengths for compound $\mathbf{1 0 g}$.

\begin{tabular}{|c|c|c|c|}
\hline Atom-Atom & Length/§̊ & Atom-Atom & Length/Å \\
\hline N2-C6 & $1.41(2)$ & C11-C12 & $1.44(3)$ \\
\hline N2-N3 & $1.31(2)$ & C11-C13 & $1.46(3)$ \\
\hline O2-N1 & $1.22(3)$ & C15-C14 & $1.49(4)$ \\
\hline 03-C13 & $1.22(2)$ & C16-C7 & $1.46(3)$ \\
\hline 04-C16 & $1.23(2)$ & C7-N3 & $1.32(2)$ \\
\hline N5-C14 & $1.49(3)$ & $\mathrm{C} 7-\mathrm{C} 8$ & $1.45(3)$ \\
\hline N5-C16 & $1.37(2)$ & $\mathrm{C} 5-\mathrm{C} 4$ & $1.38(3)$ \\
\hline N5-C13 & $1.39(3)$ & C4-C3 & $1.38(3)$ \\
\hline C6-C5 & $1.39(3)$ & $\mathrm{C} 3-\mathrm{C} 2$ & $1.37(3)$ \\
\hline C6-C1 & $1.39(3)$ & C8-C9 & $1.50(3)$ \\
\hline N1-01 & $1.22(3)$ & C12-N4 & $1.13(3)$ \\
\hline N1-C3 & $1.47(3)$ & C9-C10 & $1.50(3)$ \\
\hline C11-C8 & $1.36(3)$ & C1-C2 & $1.37(3)$ \\
\hline
\end{tabular}

Table 3. Bond Angles for compound 10g.

\begin{tabular}{llll}
\hline Table 3. Bond Angles for compound 10g. & & & Atom-Atom-Atom \\
\hline Atom-Atom-Atom & Angle $^{\circ}$ & N3-C7-C8 & Angle ${ }^{\circ}$ \\
\hline N3-N2-C6 & $120.1(15)$ & C8-C7-C16 & $116.5(17)$ \\
C16-N5-C14 & $118.3(17)$ & N2-N3-C7 & $119.9(16)$ \\
C16-N5-C13 & $123.6(16)$ & C4-C5-C6 & $120.3(16)$ \\
C13-N5-C14 & $118.0(16)$ & C3-C4-C5 & $118.9(19)$ \\
C5-C6-N2 & $121.1(18)$ & C4-C3-N1 & $119.0(18)$ \\
C5-C6-C1 & $121.2(16)$ & C2-C3-N1 & $118.7(18)$ \\
C1-C6-N2 & $117.8(16)$ & C2-C3-C4 \\
O2-N1-C3 & $118.9(19)$ & C11-C8-C7 \\
O1-N1-O2 & $123.3(19)$ & C11-C8-C9 \\
O1-N1-C3 & $118.0(20)$ & C7-C8-C9 \\
C8-C11-C12 & $121.7(17)$ & N4-C12-C11 \\
C8-C11-C13 & $124.0(18)$ & O3-C13-N5 \\
C12-C11-C13 & $114.3(17)$ & O3-C13-C11 \\
N5-C14-C15 & $111.0(20)$ & N5-C13-C11 \\
04-C16-N5 & $119.9(16)$ & C8-C9-C10 \\
04-C16-C7 & $121.8(17)$ & C2-C1-C6 \\
N5-C16-C7 & $118.3(16)$ & C1-C2-C3 \\
N3-C7-C16 & $123.5(17)$ & \\
\hline
\end{tabular}
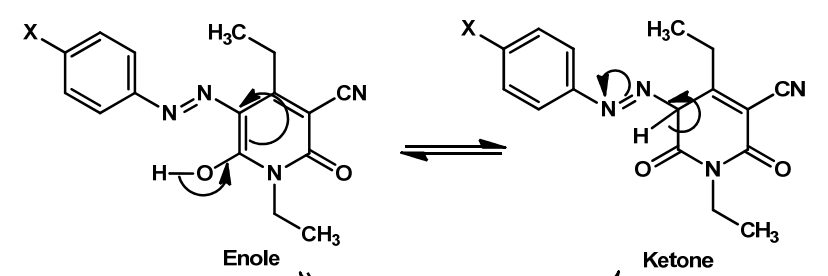

Enole

Ketone

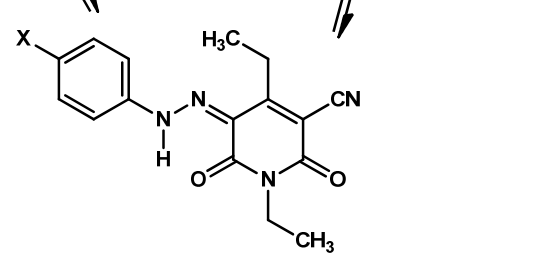

Hydro-azo

Enole - Ketone - Hydrazo Tautomerism

Scheme 3

The infrared spectra of all synthesized dyes showed two intense carbonyl bands at about 1682 and $1624 \mathrm{~cm}^{-1}$, which were assigned to the diketohydrazone form. The ${ }^{1} \mathrm{H}$ NMR spectra of the dyes provide some characteristic results to prove this. The hydrazone NH proton appeared at $14.85-14.55 \mathrm{ppm}$, which is consistent with previous report [11]. The possibility of the existence of an intramolecular hydrogen bond between the hydrazone $\mathrm{NH}$ and carbonyl $\mathrm{O}$ is also attributed to the stability of the keto-hydrazone form.

\subsection{Absorption spectral characteristics}

It is well known that $\lambda_{\max }$ values relate to the strength of the electronic power in the benzenoid system [17]. Since electronic transition in these compounds involves a general migration of electron density from the donor group towards the azo group, the greatest effect in terms of longer wavelength is achieved by placing the substituent in the position ortho or para to the azo group for effective conjugation [18]. The absorption maxima of the dyes 10a-g were measured in DMF solution are shown in (Table 4), ranged from 410 to $468 \mathrm{~nm}$. The incorporation of an electron-donating substituent at the para-position of the arylhydrazono moiety results in a significant bathochromic shift, thus, the dye 10b, 10c and 10d $\left(\lambda_{\max } 468,438\right.$ and 464 $\mathrm{nm})$, were characterized by significant bathochromic shifts compared with dye 10a $\left(\lambda_{\max } 410 \mathrm{~nm}\right)\left(\Delta \lambda_{\max }=58,28\right.$ and 54 $n m$ ), attributable to the $\mathrm{CH}_{3}, \mathrm{OCH}_{3}$ and $\mathrm{OH}$ groups, respectively. 
Table 4. Shade and optical measurements of the azo disperse dyes on the polyester fabrics.

\begin{tabular}{|c|c|c|c|c|c|c|c|c|}
\hline $\begin{array}{l}\text { Dye } \\
\text { no }\end{array}$ & Colour shade on polyester & Absorption $\left(\lambda_{\max }(\mathrm{nm})\right)$ & $L^{*}$ & $a^{*}$ & $\boldsymbol{b}^{*}$ & $C^{*}$ & $\boldsymbol{h}^{*}$ & $K / S$ \\
\hline$\overline{10 a}$ & Yellow & 410 & 83.76 & 2.86 & 108.46 & 108.5 & 88.49 & 27.39 \\
\hline $10 \mathrm{~b}$ & Dark orange & 468 & 59.35 & 45.74 & 77.22 & 89.75 & 59.36 & 30.29 \\
\hline $10 \mathrm{c}$ & Orange & 438 & 67.77 & 42.60 & 92.15 & 101.52 & 65.19 & 30.28 \\
\hline $10 \mathrm{~d}$ & Orange & 464 & 74.91 & 31.22 & 74.73 & 80.99 & 67.32 & 8.88 \\
\hline $10 \mathrm{e}$ & Yellow & 417 & 82.00 & 8.57 & 109.48 & 109.81 & 85.52 & 28.91 \\
\hline $10 \mathrm{f}$ & Dark yellow & 416 & 81.22 & 11.00 & 109.18 & 109.73 & 84.25 & 28.09 \\
\hline $10 \mathrm{~g}$ & Very dark yellow & 452 & 79.46 & 9.28 & 98.8 & 99.23 & 84.63 & 27.31 \\
\hline
\end{tabular}

Table 5. Fastness properties of azo disperse dyes on polyester fabrics*.

\begin{tabular}{|c|c|c|c|c|c|c|c|c|c|c|}
\hline \multirow[t]{3}{*}{ Dye no } & \multirow{2}{*}{\multicolumn{3}{|c|}{ Wash fastness }} & \multicolumn{6}{|c|}{ Perspiration fastness } & \multirow[t]{3}{*}{ Light fastness } \\
\hline & & & & \multicolumn{3}{|c|}{ Acid } & \multicolumn{3}{|c|}{ Alkaline } & \\
\hline & Alt & SC & SW & Alt & SC & SW & Alt & SC & SW & \\
\hline $10 \mathrm{a}$ & 5 & 5 & 5 & 5 & 5 & 5 & 5 & 5 & 5 & 4 \\
\hline $10 \mathrm{~b}$ & 5 & 5 & 5 & 5 & 5 & 5 & 5 & 5 & 5 & 2 \\
\hline $10 \mathrm{c}$ & 5 & 5 & 5 & 5 & 5 & 5 & 5 & 5 & 5 & 5 \\
\hline $10 \mathrm{~d}$ & 5 & 5 & 5 & 5 & 5 & 5 & 5 & 5 & 5 & 2 \\
\hline $10 \mathrm{e}$ & 5 & 5 & 5 & 5 & 5 & 5 & 5 & $4-5$ & 5 & $3-4$ \\
\hline $10 \mathrm{f}$ & 5 & 5 & 5 & 5 & $3-4$ & 5 & 5 & 3 & 5 & $3-4$ \\
\hline $10 \mathrm{~g}$ & 5 & 5 & 5 & 5 & 5 & 5 & 5 & 5 & 5 & 5 \\
\hline
\end{tabular}

* Alt = alteration; $\mathrm{SC}=$ staining on cotton; $\mathrm{SW}=$ staining on wool.

The incorporation of such electron-withdrawing groups as $\mathrm{Br}$ and $\mathrm{Cl}$ at the para-position of the arylhydrazono moiety, little bathochromic shift could be observed, dye 10e, and $\mathbf{1 0 f}$ $\left(\lambda_{\max } 417\right.$ and $\left.416 \mathrm{~nm}\right)$, were characterized by show a small bathochromic shifts compared with dye 10a $\left(\Delta \lambda_{\max }=7\right.$ and 8). The spectroscopic data also reveal that the incorporation of $\mathrm{NO}_{2}$ group in dye $10 \mathrm{~g}$ gave a better exhaustion and depth of colour $\left(\Delta \lambda_{\max }=42\right)$.

\subsection{Dyeing properties}

Disperse dyes 10a-g were applied to polyester fabrics at 2\% (dye shade), using high temperature dyeing method (HT) at $130{ }^{\circ} \mathrm{C}$. Yellow to dark orange colour shades were obtained. The dyeing properties on the polyester fabrics were evaluated in terms of their fastness properties (e.g., fastness to washing, perspiration and light). The color of dyeing on polyester fabrics is expressed in terms of CIELAB colour space values (Table 4), and the following CIELAB coordinates were measured: lightness or darkness $\left(L^{*}\right.$ ); brightness or dullness (chroma $\left(C^{*}\right)$ ); hue angle $(h)$ from 0 to $360^{\circ} ; a^{*}$, whose value represents the degree of redness (positive) and greenness (negative); and $b^{*}$, whose value represents the degree of yellowness (positive) and blueness (negative) [12].

The surface colour yield K/S was used to explain the amount of dye absorbed on the surface of the fibre. The K/S values listed in (Table 4) show that dyes 10a-g showed high affinity for the polyester fabrics and the K/S were all generally satisfactory. The results listed in (Table 4) demonstrate that the introduction of electron-withdrawing groups at the benzene ring improved the lightness and brightness; in contrast, the introduction of electron-donating decreased the lightness and brightness so dyes $\mathbf{1 0 e}-\mathbf{g}$ were lighter and brighter than the 10b-d. The dyeing obtained using dye 10b was more orange (as shown by the higher $a^{*}$ values, higher $b^{*}$ values and lower $h^{\circ}$ values) and brighter (as shown by the higher $C^{*}$ values) than the dyes 10d. Similarly, the dyeing obtained using dye 10c was more orange (as shown by the higher $a^{*}$ values, higher $b^{*}$ values and lower $h^{\circ}$ values) and brighter (as shown by the higher $C^{*}$ values) than the dye10d. Furthermore, the dyeing obtained using dyes 10a and 10e-g are bright yellow (as evidenced by the lower $a^{*}$ values, higher $b^{*}$ values, higher $h^{\circ}$ values and higher $C^{*}$ values).

The fastness ratings are recorded in (Table 5), shows that the disperse dyeing displayed very good fastness levels to perspiration and excellent fastness levels to washing. In general these are excellent for fabrics which had been subjected to the reduction clearing stage. However when the reduction clearing was omitted, marginally worse staining was observed [19]. This indicated that reduction clearing is important for these dyeings. As these dyes are characteristically hydrophobic, high washing and perspiration fastness ratings are expected. The light fastness of the dyes 10a-g on polyester displayed moderate fastness on polyester fabrics. The light fastness is significantly affected by the nature of the substituents in the diazonium component. The inclusion of electron-withdrawing (bromine or chorine or nitro) substituents improves the light fastness to (3-4, 3-4 and 5 , respectively). It is of value to mention here that light fastness was obtained by the dye $\mathbf{1 0 g}$ containing a nitro group in the diazonium component, the nitro group increases the polarity of the dyes [20], which may link them more strongly to the fabric and it opens an extra way for the energy dissipation after light absorption which decreases the chances for photo-fading.

\subsection{Antimicrobial activities}

The inhibition zone diameter data for the arylhydrazopyridones disperse dyes, given in Table 6, shows that all of the tested dyes showed strong positive antimicrobial activities against at least four of the tested microorganisms. Disperse dye 10a showed cytolytic effect even after 120 hours of incubation, there were no growth recorded in the inhibited zone for all five tested microbes.

\section{Conclusion}

In summary, 1,4-diethyl-2,6-dioxo-1,2,5,6-tetrahydro pyridine-3-carbonitrile $\mathbf{9}$, is synthesized by three component condensation of ethyl cyanoacetate, ethyl amine and methyl propionylacetate under microwave irradiation. Compound 9 coupled with aromatic diazonium salts to give the corresponding arylhydrazono-1,4-diethyl-2,6-dioxo-1,2,5,6tetrahydropyridine-3-carbonitrile disperse dyes. The dyes produced in this manner were then applied to polyester fabrics by using high temperature dyeing method at $130^{\circ} \mathrm{C}$. The dyed fabrics displayed yellow to dark orange on polyester fabrics, have moderate, very good and excellent fastness levels to light, perspiration and washing, respectively. Finally, the biological activities of the synthesized disperse dyes against Gram positive bacteria; Gram negative bacteria and yeast were discussed. Comparison between conventional and microwave dyeing, for these arylhydrazopyridones disperse dyes are under investigation. 
Table 6. Inhibition zone diameter of the tested arylhydrazopyridones disperse dyes that showed strong antimicrobial activities against the tested microorganisms.

\begin{tabular}{|c|c|c|c|c|c|}
\hline \multirow[t]{3}{*}{ Compound no } & \multicolumn{5}{|c|}{ Inhibition zone diameter (Nearest mm) c } \\
\hline & \multicolumn{2}{|c|}{ G+ bacteria } & \multicolumn{2}{|l|}{ G- bacteria } & \multirow{2}{*}{$\begin{array}{l}\text { Fungi } \\
\text { C. albicans } \\
\text { Mean } \pm \text { SD } \\
\end{array}$} \\
\hline & $\begin{array}{l}\text { B. subtilis } \\
\text { Mean } \pm \text { SD }\end{array}$ & $\begin{array}{l}\text { S. aureus } \\
\text { Mean } \pm \text { SD }\end{array}$ & $\begin{array}{l}\text { E. coli } \\
\text { Mean } \pm \text { SD }\end{array}$ & $\begin{array}{l}\text { P. aeruginosa } \\
\text { Mean } \pm \text { SD }\end{array}$ & \\
\hline$\overline{10 a}$ & $12.2(0.5)$ & $13.3(0.9)$ & $14(1)$ & $16.6(0.2)$ & $14(0.3)$ \\
\hline $10 \mathrm{~b}$ & $9(0.3)$ & $10(0.3)$ & $10.8(1.5)$ & $11.6(0.2)$ & $12(1)$ \\
\hline 10c & $10.8(0.5)$ & $14.1(1)$ & $12.1(0.7)$ & $10.6(0.2)$ & $19.1(1.3)$ \\
\hline $10 \mathrm{~d}$ & $14.6(0.5)$ & $13.7(0.6)$ & $15(0.5)$ & $17.2(1.4)$ & $10.1(0.5)$ \\
\hline $10 \mathrm{e}$ & $9(0.2)$ & NId & $10(0.6)$ & $9.1(0.4)$ & $12.7(0.6)$ \\
\hline $10 \mathrm{f}$ & NId & $11.1(0.7)$ & $10(0.4)$ & NId & $20.4(0.7)$ \\
\hline $10 \mathrm{~g}$ & $9.7(0.5)$ & $10.7(1.2)$ & $11(0.6)$ & $9.4(0.2)$ & $16.2(1)$ \\
\hline Ampicillin a & $16(0.5)$ & $15(1)$ & $18.6(1.3)$ & $18.4(3.5)$ & - \\
\hline Cyloheximide b & - & - & - & - & $\mathrm{NId}$ \\
\hline
\end{tabular}

a Ampicillin: Antibacterial $(100 \mathrm{mg} / \mathrm{mL})$

b Cycloheximide: Antifungal $(100 \mathrm{mg} / \mathrm{mL})$,

c NI: No inhibition.

d SD = Standard Deviation.

\section{Supplementary material}

CCDC-930799 of compound $\mathbf{1 0 g}$ contains the supplementary crystallographic data for this paper. These data can be obtained free of charge via www.ccdc.cam.ac.uk/ data request/cif, or by e-mailing data request@ccdc.cam.ac.uk, or by contacting The Cambridge Crystallographic Data Centre, 12 Union Road, Cambridge CB2 1EZ, UK; fax: +44(0)1223336033.

\section{Acknowledgements}

The facilities of (General Facility of Science GF-S) provided by Kuwait University, supported by research grants (GS03/08), (GS01/01), (GS01/03) and (GS01/05) are highly appreciated.

\section{References}

[1]. Faustino, H.; Brannigan, C. R.; Reis, L. V.; Santos, P. F.; Almeida, P. Dyes Pigments 2009, 83, 88-94.

[2]. Jia, R.; Zheng, C.; Yang, D.; Sun, J.; Wang, H. Color. Technol. 2012, 128(4), 290-294.

[3]. Rangnekar, D. W.; Dhamnskar, S. V. Dyes Pigments 1990, 13(4), 241250.

[4]. Nermin, E.; Fatih, E. Dyes Pigments 1995, 27(4), 313-320.

[5]. Bahatti, H. S.; Seshadri, S. Color. Technol. 2004, 120(4), 151-155.

[6]. Yen, M. S.; Wang, I. J. Dyes Pigments 2004, 61(3), 243-250.

[7]. Song, H. C. K.; Tian, H. Dyes Pigments 2002, 53(3), 257-262.

[8]. Chien, C. C.; Wang, I. J. Dyes Pigments 1991, 15, 69-82.

[9]. Ertan, N.; Gurkan, P. Dyes Pigments 1997, 33, 137-147.

[10]. Ashkar, S. M.; El-Apasery, M. A.; Touma, M. M.; Elnagdi, M. H. Molecules 2012, 17, 8822-8831.

[11]. Al-Etaibi, A.; El-Apasery, M. A.; Al-Awadi, N. Eur. J. Chem. 2013, 4(3), 240-244.

[12]. Al-Mousawi, S. M.; El-Apasery, M. A.; Mahmoud, H. M. Molecules 2013, 18, 7081-7092.

[13]. Chrysler, L. P. Methods of Test for Color Fastness of Textiles and Leather, 7th ed., Bradford, London 1990, pp. 89-94.

[14]. El-Apasery, M. A.; Al-Qalaf, F.; Almohammad, K.; Mahmoud, H. Eur. J. Chem. 2013, 4(3), 211-215.

[15]. Isaacson, D. M.; Kirschbaum, J. Assays of antimicrobial substances In: Manual of Industrial Microbiology and Biotechnology (Demain, A. L.; Solomon, N. A.; Eds), ASM, 1986, 410-435.

[16]. Elguero, J.; Marzin, C.; Katritzky, A. R.; Linda, P. The Tautomerism of Heterocyles in Adv. Heterocycl. Chem., Academic Press, 1976, pp. 106109.

[17]. Karci, F.; Karci, F. Dyes Pigments. 2008, 76(1), 147-157.

[18]. Otutu, J. 0.; Osabohien, E. Asian J. Mat. Sci. 2013, 5(1), 1-8.

[19]. Singh, K.; Singh, S.; Taylor, J. A. Dyes Pigments. 2002, 54, 189-200.

[20]. Metwally, M. A.; Abdel-latif, E.; Amer, F. A.; Kaupp, G. Dyes Pigments 2004, 60, 249-264. 